\title{
Comparison of Rapid Quantification of Aviation Kerosene by Short-Wave and Long-wave Near-Infrared Spectroscopy
}

\author{
Xing Zhi-Na*, Wang Ju-Xiang, Liu Jie and Shen Gang
}

Department of Airborne Vehicle Engineering, Naval Aeronautical and Astronautical University, Yantai, Shandong, China, 264001

\begin{abstract}
The application of short-wave NIRS (SW-NIRS) in determining acidity of aviation kerosene was described in term of chemometrics, and compared with long-wave NIRS (LW-NIRS). The standard error of prediction (SEP) of SWNIRS and LW-NIRS were $0.097 \mathrm{mgKOH} / 100 \mathrm{~mL}$ and $0.091 \mathrm{mgKOH} / 100 \mathrm{~mL}$ respectively. A $t$-test showed that the SWNIRS model and LW-NIRS one all had an accuracy equivalent to that of GB/T7304 in the analysis of acidity of aviation kerosene. However the SW-NIRS method had the particular advantage of cheaper analysis cost than LW-NIRS. In results, SW-NIRS possessed the important application significance in the course of general test and production monitor.
\end{abstract}

Keywords: Aviation kerosene, acidity, shortwave near infrared spectroscopy (SW-NIRS), long wave near infrared spectroscopy (LW-NIRS), comparison.

\section{INTRODUCTION}

Acidity is a significant parameter showing the gross acid content (water-soluble acid and macromolecule organic acid) in aviation kerosene. The acidity xpresses the content of macromolecule organic acid normally because aviation kerosene doesn't contain water-soluble acid as leaving from factory. Macromolecule organic acid mainly contains naphthenic acid, excessiveness of which may corrode metal material seriously. This acidity of aviation kerosene must be determined before it is used. The traditional method (GB/T 7304, which is equal to ASTM D 664), a typical acid-base titration, to determine the acidity of aviation kerosene fulfills the necessary requirements of accuracy, specificity, and reproducibility but it is very time-consuming, requiring a plenty of glass apparatuses and multiplicate reagent.

Near-infrared (NIR) absorption is attributed mainly to overtones and combinations of mid-IR vibrational bands involving $\mathrm{N}-\mathrm{H}, \mathrm{O}-\mathrm{H}$, and $\mathrm{C}-\mathrm{H}$ bonds in molecules. The acidity is more related to the ingredient of aviation kerosene. Then NIRS has been used to determined the acid of fruits successfully [1-3]. The NIR region is divided as LW-NIR situated in region between $1,100-2,500 \mathrm{~nm}$ and SW-NIR situated in region between 700-1,100nm [4]. The spectral information of LW-NIR is rather rich.

However, the LW-NIR instrument is expensive due to costly detector and light sources. The SW-NIRS has greatly decreased absorptivities but has the distinct advantages that it can be transmitted over inexpensive fiber optics, can utilize long path lengths $(1-5 \mathrm{~cm})$, and can be measured with very inexpensive light sources (tungsten lamps) and detectors (silicon diode array or silicon charger coupled

*Address correspondence to this author at the NO.188 ErMaLu, Zhifu district, Yantai, Shandong, China. Postcard: 264001. Tel.: 0535-6635578 to 8006. E-mail: zhnxing2008@163.com device, shorted for CCD) [5]. The relative weak absorb strength make SW-NIRS perfect to general quantitative analyse [6]. The UV-visible light spectrophotometer whose spectrum range extending to1,100 $\mathrm{nm}$ can acquire the SWNIR spectrum simply. Thereby, the study of SW-NIRS application is significant in practice.

The aim of this paper is to describe the manner in which a robust SW-NIRS method has been used to determine acidity and to develop a rapid and relatively inexpensive method.

\section{EXPERIMENTAL SECTION}

\subsection{Instrumentation}

SW-NIR spectra were acquired using a NIR-2000 spectra instrument with a transmission silica detector $(\mathrm{CCD} / 2048$ pixels) in a useable wavelength range of 700-1,100 nm. LWNIR spectra were acquired using SupNIR-2600 with a transmission InGaSe detector in a useable wavelength range of 1,000-1,800 nm. All measurements were performed using air as reference.

\subsection{Sample Preparation}

Total 38 samples $(0.09-0.36 \mathrm{mgKOH} / 100 \mathrm{~mL})$ were collected from three different manufactures of aviation kerosene in China. A group of 32 samples was taken to develop the SW-NIR calibration model and LW-NIR one respectively. The other 6 samples formed a validation set (viz., accuracy set) to test the calibration model. All samples were tested for acidity with GB/T 7304 by the means of the typical acid-base titration. This was the laboratory reference method for analysis of samples employed as standards for NIRS calibration development.

\subsection{Sample Spectra Collection}

Figs. (1) and (2) showed the SW-NIRS curve and LWNIRS curves of aviation kerosene respectively. 


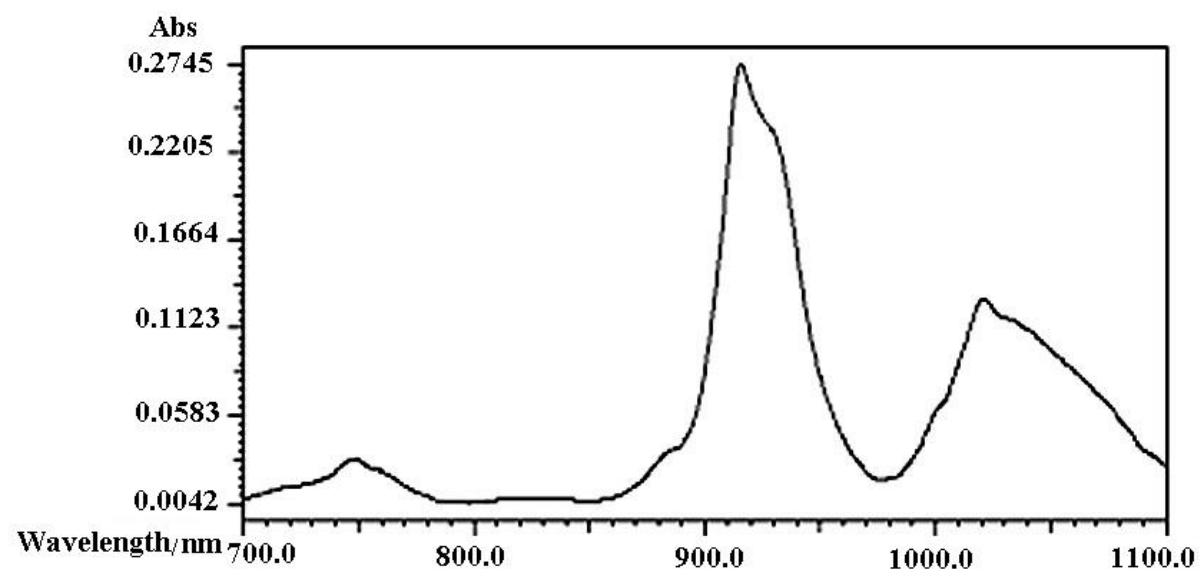

Fig. (1). SW-NIRS curve of aviation kerosene.

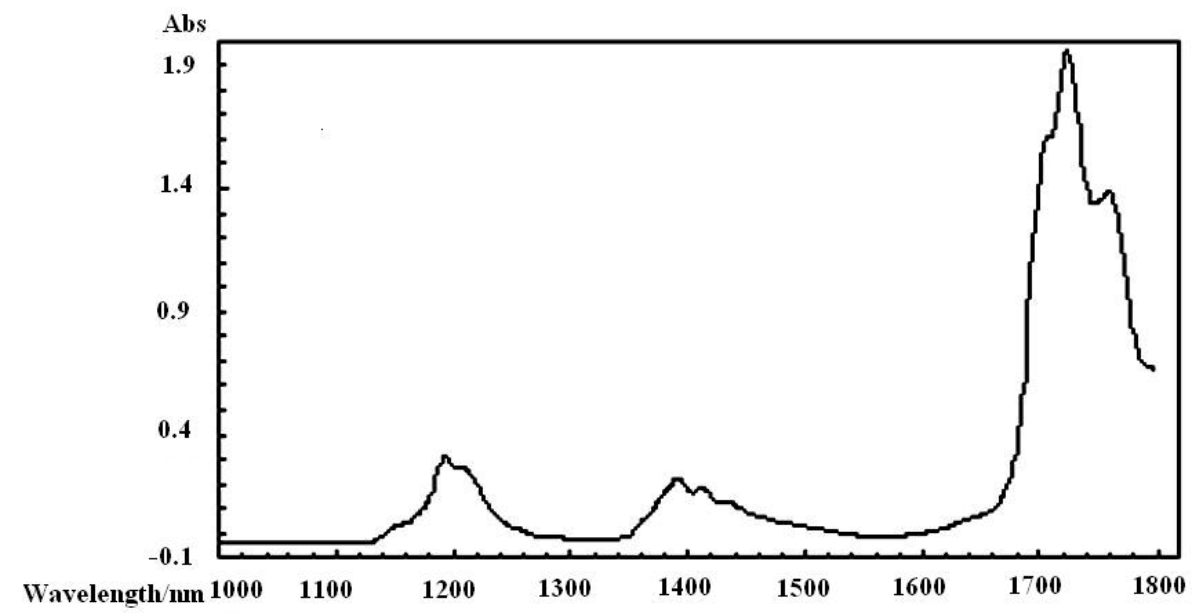

Fig. (2). LW-NIRS curve of aviation kerosene.

\section{RESULTS AND DISCUSSION}

\subsection{Development of a Calibration Model}

The calibration algorithm for calibration model of SWNIRS and LW-NIRS were partial least squares (PLS) provided by the NIR systems software package with the instrument. While the basic NIR absorption spectra may be used for calibration purposes, often some pretreatment of the sample spectra were used to remove the influence of random noise, decrease the systematic error, and increase the signal to - noise ratio (SNR). The optimal spectral range and model size were then selected on the basis of the minimum prediction residual error sum of squares (PRESS). Full crossvalidation following the leave-one-out procedure was performed to determine the optimum number of factors for the model. A certain minimum number of factors were then used to find a suitable calibration. The parameters of models were shown in Table $\mathbf{1 .}$

The correlation between the reference values calculated from GB/T 7304 analyses and the predicted values received from the SW-NIRS and LW-NIRS calibration model were shown in Figs. $(\mathbf{3}, \mathbf{4})$. The $\mathrm{R}^{2}$ of SW-NIRS and LW-NIRS

Table 1. Parameters of Models

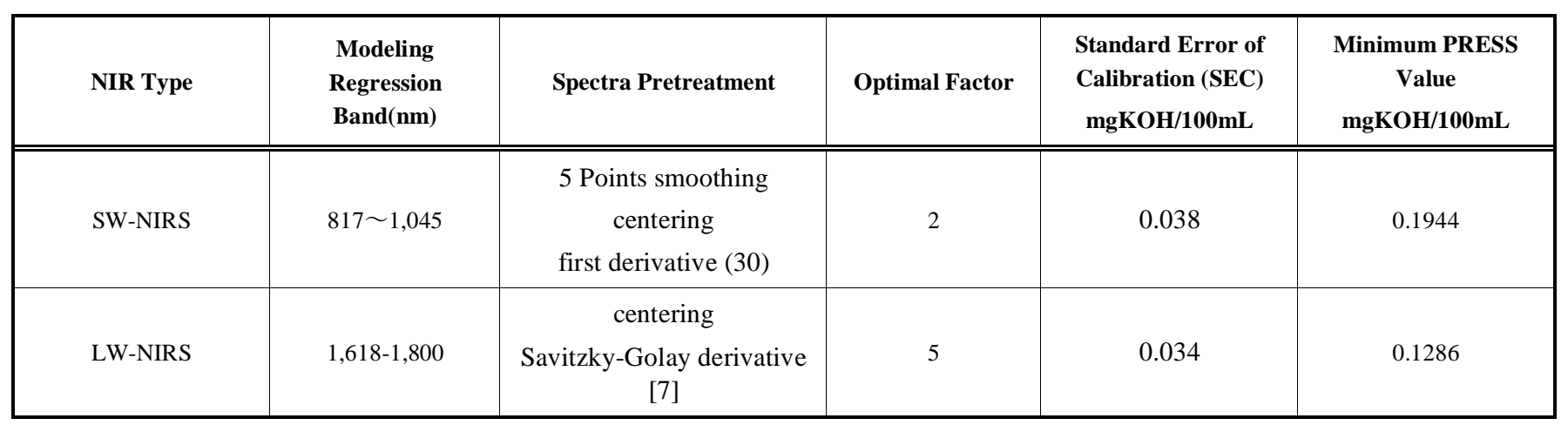




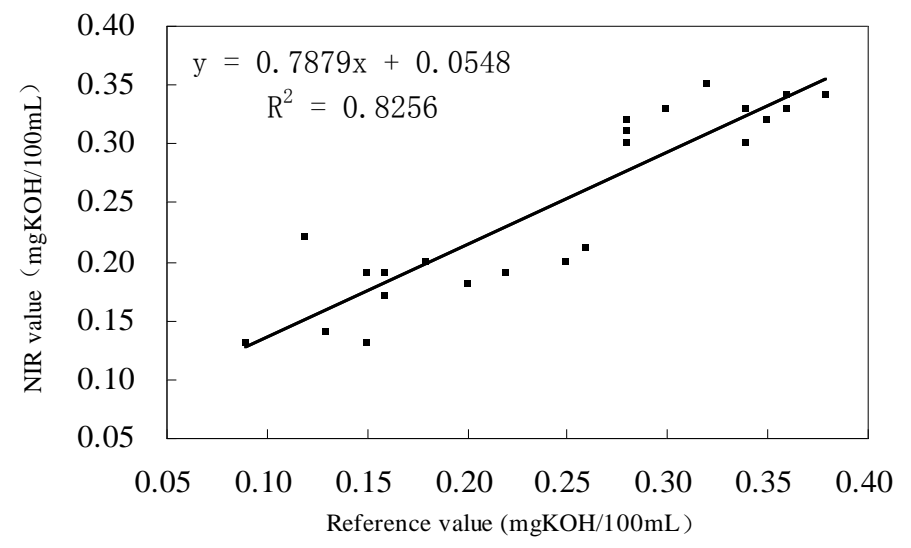

Fig. (3). Calibration curve of SW-NIRS predicted model.

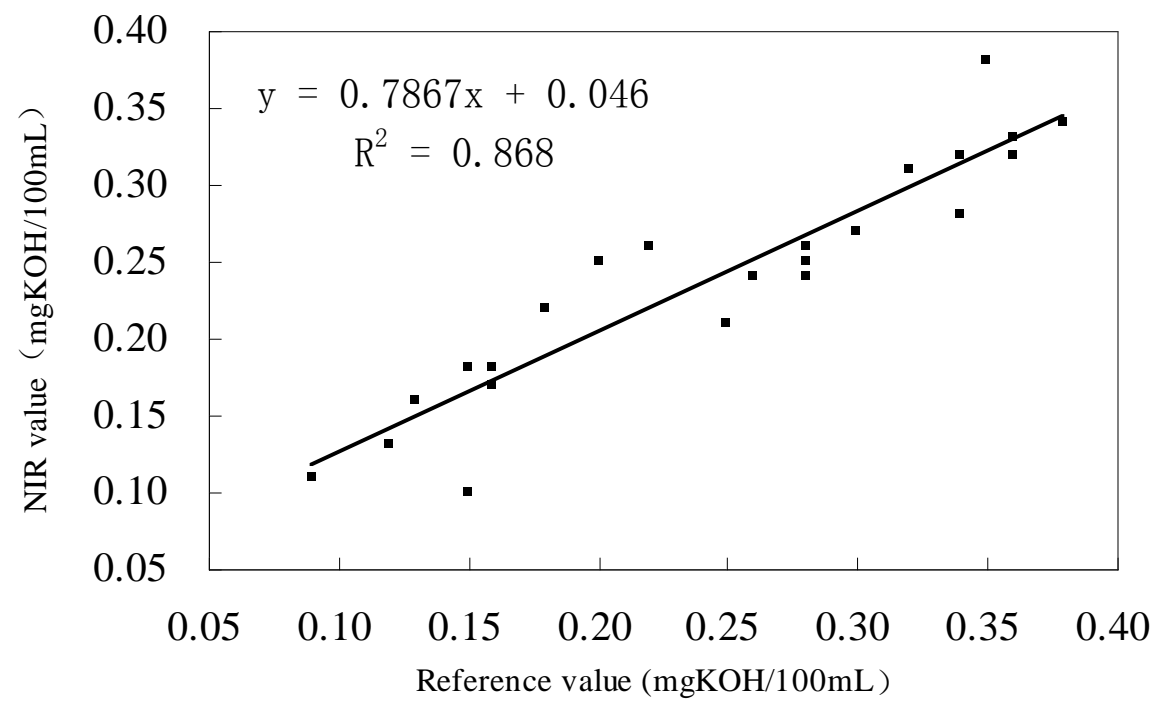

Fig. (4). Calibration curve of LW-NIRS predicted model.

model were 0.8256 and 0.8680 respectively. The calibration model of SW-NIRS had the good relevance between data and spectrum similar to LW-NIRS.

\subsection{Accuracy Comparison of SW-NIRS Model and LW- NIRS Model}

The accuracy of the NIRS model was analyzed by Student's $t$-test. If the difference between NIRS method and routine method was statistically significant at the $95 \%$ confidence $(\alpha=0.05)$ level, the result underscored the importance of NIRS method accuracy with an independent set of samples prior to routine method.

The 6 samples belonging to the validation set were chosen in order to test the accuracy of the calibration model. A comparison of the values reported between the SW-NIRS

Table 2. Comparison of Results Determined by SW-NIRS and LW-NIRS（mgKOH/100m）

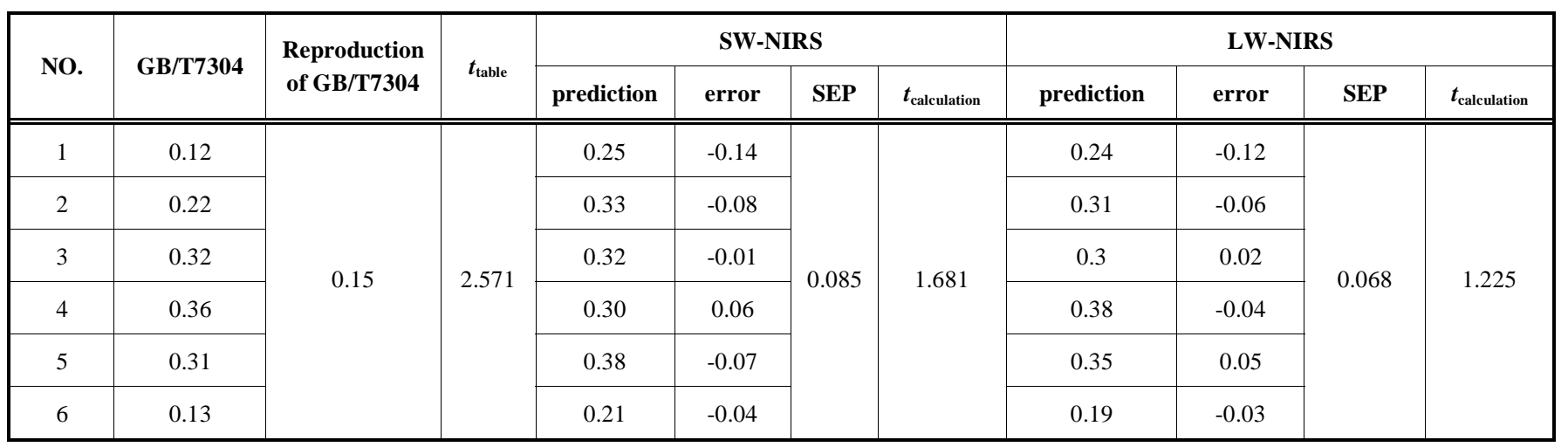


Table 3. Precision of the SW-NIRS Model

\begin{tabular}{|c|c|c|c|c|}
\hline $\begin{array}{l}\text { Determination of } \\
\text { SW-NIRS }\end{array}$ & $\begin{array}{c}\text { SW-NIRS } \\
(\mathrm{mgKOH} / 100 \mathrm{~mL})\end{array}$ & $\begin{array}{c}\text { Reference Value of GB/T7304 } \\
(\mathrm{mgKOH} / 100 \mathrm{~mL})\end{array}$ & $\begin{array}{c}\text { Standard Error } \\
\text { of Replicates } \\
(\mathrm{mgKOH} / 100 \mathrm{~mL})\end{array}$ & $\begin{array}{c}\text { Reproduction } \\
\text { of GB/T7304 } \\
(\mathrm{mgKOH} / 100 \mathrm{~mL})\end{array}$ \\
\hline 1 & 0.23 & \multirow{7}{*}{0.31} & \multirow{7}{*}{0.08} & \multirow{7}{*}{0.15} \\
\hline 2 & 0.23 & & & \\
\hline 3 & 0.25 & & & \\
\hline 4 & 0.22 & & & \\
\hline 5 & 0.27 & & & \\
\hline 6 & 0.25 & & & \\
\hline 7 & 0.24 & & & \\
\hline
\end{tabular}

and LW-NIRS with those of the laboratory reference method presented in Table $\mathbf{2}$ was carried out.

This difference between NIRS and GB/T 7304 was statistically significant at the $95 \%$ confidence $(\alpha=0.05)$ level because $t_{\text {calculation values of SW-NIRS and LW-NIRS, which }}$ were 1.681 and 1.225 , were all below $t_{\text {talbe }}=2.571$. The SEP of SW-NIRS was a bit bigger than that of LW-NIRS. However the SW-NIRS model had the precision similar to GB/T7304. Then it can be an alternate to replace LW-NIRS in acidity determination of aviation kerosene.

\subsection{Precision of the SW-NIRS Model}

To demonstrate the repeatability of the SW-NIRS method, a single sample of aviation kerosene was analyzed seven times repeatedly. Table $\mathbf{3}$ summarized the data obtained for replicate analysis of it, along with the expected "true" value of the laboratory reference method.

It was evident, given the low standard deviation values (seen in Table 3), that this method performed well during replicate testing with high precision.

\section{CONCLUSIONS}

1. In the present study, it was verified that the SW-NIR spectrometer can be used to quantify the acidity of aviation kerosene with precision similar to GB/T 7304 .
2. SW-NIRS has the practical value due to the distinct advantages of less expensive instruments and similar precision to LW-NIRS.

\section{REFERENCES}

[1] Y. D. Liu, Y. B. Ying, and X. P. Fu, "Study on Predicting Sugar Content and Valid Acidity of Apples by Near Infrared Diffuse Reflectance Technique", J. Spectrosc. Spectral. Anal., vol. 25, pp. 1793, 2005.

[2] Y. N. Shao, and Y. He, "Nondestructive measurement of the internal quality of bayberry juice using Vis/NIR spectroscopy", $J$. Food Eng., vol. 79, pp. 1015, 2007.

[3] Y. D. Liu, Y. B. Ying, and H. Y. Jiang, "Rapid determination of maturity in apple using outlier detection and calibration model optimization", J. Trans. ASABE, vol. 49, pp. 91, 2006.

[4] D. A. Skoog, J. F. Holler, and T. A. Nieman, "Principles of instrumental analysis", 5th ed. Saunders College Publ: Philadelphia, pp. 422-430, 1998.

[5] J. K. Jeffrey, and B. C. James, "Nondestructive analytical procedure for simultaneous estimation of the major classes of hydrocarbon constituents of finished gasoline", Anal. Chem., vol. 62, pp. 1444-1451, 1990.

[6] J. H. Pang, L. R. Teng, and F. M. Jiang, "Rapid determination of ehtanol in wine by short-wavelength near-infrared spectroscopy", $J$ Jilin Univer Sci Ed., vol. 41, No. 2, pp. 245, 2003.

[7] Y. L. Yan, Near-Infrared Spectroscopy Analysis and Application, Beijing: China Light Industry Press, vol. 9, pp. 103, 2005. 